\title{
Associations among Lipoprotein (a) and Apolipoproteins (A1, B100, E) Status in Bangladeshi Patients with Cholelithiasis and Effects of Laparoscopic Cholecystectomy on the Status
}

\author{
ASM Giasuddin ${ }^{1 *}$, KA Jhuma², MAM Chowdhury ${ }^{3}$ and AMM Haq ${ }^{4}$ \\ ${ }^{1}$ Professor of Biochemistry \& Immunology \& Director, Medical Research Unit (MRU), Medical College for Women \& Hospital (MCW\&H) Building, MHWT, \\ Uttar, Dhaka, Bangladesh \\ ${ }^{2}$ Professor, Department of Biochemistry \& Molecular Biology, MCW\&H, Member Secretary of MRU, MHWT, Uttara, Dhaka, Bangladesh \\ ${ }^{3}$ Associate Professor, Department of Surgery, MCW\&H, MHWT, Uttara, Dhaka, Bangladesh \\ ${ }^{4}$ Honorary Professor, Department of Internal Medicine, MCW\&H and Chairman of MRU, MHWT, Uttara, Dhaka, Bangladesh
}

*Corresponding author: Prof. Dr. ASM Giasuddin, Professor \& Senior Consultant in Laboratory Medicine (Biochemistry \& Immunology), Impulse Hospital, ImHS\&RCLtd, 304/E Tejgaon Industrial Area, Dhaka-1208, Bangladesh.

To Cite This Article: ASM Giasuddin, KA Jhuma, MAM Chowdhury, AMM Haq, Associations among Lipoprotein (a) and Apolipoproteins (A1, B100, E) Status in Bangladeshi Patients with Cholelithiasis and Effects of Laparoscopic Cholecystectomy on the Status. Am J Biomed Sci \& Res. 2021 - 12(1). AJBSR.MS.ID.001710. DOI: 10.34297/AJBSR.2021.12.001710.

Received: 㘹 January 21, 2021; Published: 眥 February 17, 2021

\begin{abstract}
Objectives: To evaluate associations among Lp(a), ApoA1, ApoB100 and ApoE status between adult normal control subjects (NCs) and Cholelithiasis i.e. gallstone disease (GD) patients (Pts) preoperatively $\left(\mathrm{I}^{0}\right)$ and postoperatively $\left(\mathrm{II}^{0}\right)$ with laparoscopic cholecystectomy.

Patients and Methods: Adult Pts (N= 55, Gender: 10 males, 45 females; Age range: 25-65 years, mean age \pm SD: $45.5 \pm 12.2$ years) with GD and 40 NCs (Gender: 16 males, 24 females; Age range: 28-60 years; Mean age \pm SD: 42.5+10.5 years) were included the case-control prospective interventional studies. The patients with GD were diagnosed according to standard clinical and laboratory criteria. Analysis of lipid profile (TG, TC, HDL-C, LDL-C), Lp(a), ApoA1, ApoB100, ApoE, Mucin1 and CETP status in serum of NCs and Pts $\left(\mathrm{I}^{0}, \mathrm{II}^{0}\right)$ and Pts bile $\left(\mathrm{I}^{0}\right)$ were made by standard clinical laboratory methods using research/diagnostic kits from reputed companies. Advanced statistical analyses were made by SPSS programme - version 26 to obtain information for associations among Lp(a), ApoA1, ApoB100 and ApoE status in NCs and Pts.

Results: Regarding associations among Lp(a) status between NCs, Pts $\left(\mathrm{I}^{0}\right)$ and Pts $\left(\mathrm{II}^{0}\right)$, significant Pearson corrections were obtained for PtsLp(a) $\left.\left(I^{0}\right)\right)$ vs Pts-Lp(a) $\left(I^{0}\right)(r=0.851, P=0.000)$, and Pts-Lp(a) (Bile- $\left.\mathrm{I}^{0}\right)$. About associations for ApoA1 levels between NCs and Pts, no significant correlations were noted among the groups compared $(\mathrm{P}>0.05)$. Associations for ApoB100 levels between NCs and Pts showed significant Pearson correlation between NCs-ApoB100 $\left(\mathrm{I}^{0}\right)$ vs Pts-ApoB100 $\left(\mathrm{I}^{0}\right)(\mathrm{r}=0.430, \mathrm{P}=0.022)$. No significant Pearson correlations were obtained for ApoE levels in any of the groups compared $(\mathrm{P}>0.05)$. Associations among $\mathrm{Lp}(\mathrm{a})$ status and ApoA1 levels between NCs, $\mathrm{Pts}\left(\mathrm{I}^{0}\right)$ and Pts $\left(\mathrm{II}^{\circ}\right)$ showed no significant correlations among any of the groups compared $(\mathrm{P}>0.05)$. Associations (correlations) among Lp(a) status and ApoB100 between NCs, Pts $\left(\mathrm{I}^{0}\right)$ and $\left(\mathrm{II}^{0}\right)$ indicated significant correlations between Pts- ApoB100 $\left(\mathrm{II}^{0}\right)$ and Pts-Lp(a) (Bile- $\left.\mathrm{I}^{0}\right)(\mathrm{r}=0.381, \mathrm{P}=0.05)$ and between NC-Lp(a) $\left.\left(\mathrm{I}^{0}\right)\right)$ and PtsApoB100 $\left(\mathrm{II}^{0}\right)(\mathrm{r}=0.358, \mathrm{P}=0.05)$. Finally, significant Pearson correlation was obtained for NC-Lp(a) (I0) vs Pts-ApoE $\left(\mathrm{II}^{0}\right)(\mathrm{r}=-0.447, \mathrm{P}=0.050)$ and other correlations were not significant $(\mathrm{P}>0.05)$.
\end{abstract}

Conclusions: The findings on associations among the parameters between NCs and Pts $\left(\mathrm{I}^{0}, \mathrm{II}^{0}\right)$ suggested their involvements in the aetiopathogenesis of the disease. They were discussed in the light of recent knowledge for altered Lp(a) and Apolipoproteins status and molecular events in the pathogenesis of GD.

Keywords: Lipoprotein (a); Apolipoproteins; Cholelithiasis; Gallstone disease; Cholecystectomy 


\section{Introduction}

Cholelithiasis i.e. gallstone disease (GD) is one of the common gastrointestinal disorders prevalent in about $10-15 \%$ of adults in the developing countries. Cholecystectomy, i.e. surgical removal of the gallbladder and gallstones, is the treatment of choice currently. Studies over many years ago showed that more than $50 \%$ of patients with gallstone would have lipid disorder. The disease mechanism i.e. pathogenesis of cholesterol gallstone is widely accepted as an altered lipid metabolism, because of which there is a relative increase in the cholesterol levels compared to other lipids secreted by the liver into the bile [1-3]. Association between gallstones and altered lipid profile and hypomotility of the gallbladder have been reported in some studies [4-7].

Lipoprotein (a) $[\operatorname{Lp}(\mathrm{a})]$ has been implicated as a probable cause for atherosclerosis [2,3]. Based on the similarity of $\mathrm{Lp}(\mathrm{a})$ to both low density lipoprotein (LDL) and plasminogen, ithas been hypothesized that the function of $\operatorname{Lp}(\mathrm{a})$ may represent a link between the fields of atherosclerosis and thrombosis [1-3,5]. Apolipoproteins A1 (ApoA1) and ApoE and Mucin and cholesterol ester transfer protein (CETP) have been implicated with cholelithiasis in many studies $[2,7,8]$. High density lipoprotein-cholesterol (HDL-C), very low-density lipoprotein-cholesterol (VLDL-C) and Lp(a) were implicated with coronary artery disease (CAD), diabetes mellitus (DM), polycystic ovarian syndrome (POS) [1,9-12]. Higher levels of Lp(a), leptin, ApoB and malondialdehyde (MDA) and lower levels of HDL-C and paraoxonase activity were reported to be associated in cholelithiasis $[13,14]$. Each class of lipoprotein, i.e. Chylomicron, VLDL, intermediate density lipoprotein (IDL), LDL, HDL and $\mathrm{Lp}(\mathrm{a})$, carries several apolipoproteins in different proportions such as ApoA1 in HDL and chylomicron, ApoB100 in LDL, VLDL, IDL and Lp(a), ApoB48 in Chylomicron and ApoE in VLDL and IDL. Structural features of apolipoproteins enable them to bind to lipid end and still interact with the surrounding aqueous environment $[1,2]$.

Literature review indicated limited studies were reported on serum Lp(a) levels in some populations including Indian subcontinent $[15,16]$. Literature review also indicated that some of the apolipoproteins such as ApoA1, ApoB100 and ApoE and also Mucin and CETP are involved in the process of GD as well $[14,17,18]$. And GD is a metabolic problem which correlates with lipid abnormalities, adiposity, DM, hypertension and metabolic syndrome $[17,18]$. The molecular events that underlie these processes have not been understood completely, although associations between gallstones and altered lipid profile has been shown in some studies $[2,5,18]$. However, these results were variable and need confirmation by further studies in cholelithiasis patients.
With these literature background, we studied in phases from October 2016 to March 2018 various aspects of lipid profile, Lp(a) status, apolipoproteins (A1, B100, E), mucin1 and CETP statsus in cholelithiasis patients followed by cholecystectomy at Medical Research Unit (MRU), MHWT, Dhaka, Bangladesh. We reported the results on lipid profile, i.e., triglyceride (TG), total cholesterol (TC), LDL-cholesterol (LDL-C) and HDL-cholesterol (HDL-C) in serum and bile of cholelithiasis patients before cholecystectomy $\left(\mathrm{I}^{0}\right)$ and after cholecystectomy $\left(\mathrm{II}^{0}\right)$ and in normal control subjects. Also, we reported results on Lp(a) status, Apolipoproteins (ApoA1, ApoB100, ApoE) levels and Mucin1 and CETP status in serum and bile of the same patients with cholelithiasis preoperatively $\left(\mathrm{I}^{0}\right)$ and postoperatively $\left(\mathrm{II}^{0}\right)$ [19-22].

We conducted rigorous statistical analysis of these results for associations (correlations) among the above stated parameters between NCs and Pts before $\left(\mathrm{I}^{0}\right)$ and after $\left(\mathrm{II}^{0}\right)$ laparoscopic cholecystectomy using advanced SPSS programme-version 26 . As it would be bulky and lengthy, we decided to report the results of these analyses in multiple articles. Therefore, the results on "Associations among Lp(a) status and apolipoproteins (A1, B100, E) and effects of laparoscopic cholecystectomy on them in Bangladeshi patients with cholelithiasis" were reported and discussed in the present article.

\section{Patients and Methods}

Adult patients ( $N=55$, Gender: 10 males, 45 females; Age range: $25-65$ years, Mean age \pm SD: $45.5 \pm 12.2$ years) with cholelithiasis i.e. GD (Pts) and 40 healthy adult normal controls (Gender: 16 males, 24 females; Age range: 28-60 years; Mean age \pm SD: $42.5+10.5$ years) (NCs) were included in our case-control prospective interventional studies. The patients with GD were diagnosed as having cholelithiasis according to standard clinical and laboratory criteria as practiced in hospital and patients not fulfilling the criteria were excluded from the study [19-22]. After obtaining consent, patient's demographic details and clinical findings were recorded as per 'PROFORMA' at diagnosis.

The fasting blood samples were taken at diagnosis before cholecystectomy, and conducted routine laboratory tests. The serum separated was aliquoted and stored frozen at $-80^{\circ} \mathrm{C}$ as first degree serum sample $\left(\mathrm{I}^{0}\right)$. At the time of cholecystectomy, gall bladder bile was also collected from the same patient, centrifuged, aliquoted and stored frozen at $-80^{\circ} \mathrm{C}$ as first degree bile sample $\left(\mathrm{I}^{0}\right)$. After Cholecystectomy, medications were given as required for the patients. After 2-3 months at follow-up, fasting blood sample was taken again from the same patient, serum separated, aliquoted and stored frozen at $-80^{\circ} \mathrm{C}$ as second degree serum sample ( $\left.\mathrm{II}^{0}\right)$ until analyzed for lipid profile (i.e. TG, TC, HDL-C, LDL-C), Lp(a) status, apolipoproteins (ApoA1, ApoB100, ApoE), Mucin1 and 
CETP quantitatively by standard medical laboratory methods using research/diagnostic kits from internationally reputed companies (Shanghai Yehnua Biological Technology Co Ltd, China) and LDL-C calculated by Fried Wald formula [21-23]. The results of laboratory analyses in biological specimens of Pts $\left(\mathrm{I}^{0}, \mathrm{II}^{0}\right)$ and NCs were compared statistically by Student's t-test and Chi-squared $(\chi 2)$ test using SPSS programme Version 16 [24]. And the results on lipid profile, Lp(a), apolipoproteins, mucin 1 and CETP were published in our previous articles recently $[19,20,21,22]$. These research projects were carried out at Medical Research Unit (MRU), Medical College for Women \& Hospital (MCW\&H) Building, The Medical \& Health Welfare Trust (MHWT), Dhaka, Bangladesh in collaboration with Depart of Surgery, MCW\&H, Dhaka, Bangladesh from October 2016 to March 2018. Advanced statistical analyses on these results were made regarding associations (correlations) among various parameters between NCs and Pts $\left(\mathrm{I}^{0}, \mathrm{II}^{0}\right)$ by using SPSS programmeversion 26 . The data obtained relevant to associations (correlations) among Lp(a) status and apolipoproteins (A1, B100, E) and effects of laparoscopic cholecystectomy on them in Bangladeshi patients with GD i.e. cholelithiasis were reported in the present article.

\section{Results}

Our results on Lp(a) status and their statistical analyses showed that Lp(a) was much elevated in patients $\left(\right.$ serum $\mathrm{I}^{0}$ ) compared to NCs $(\mathrm{P}<0.001)$. This was lowered after laparoscopic cholecystectomy but remained elevated in patients (serum- $\mathrm{II}^{0}$ ) compared to NCs significantly $(\mathrm{P}<0.001)$. ApoA1 level was significantly reduced in our Pts which was raised significantly after 2-3 months of laparoscopic cholecystectomy, but not to the full extent similar to NCs and bile (Pts) contained lower level of ApoA1 $(\mathrm{P}<0.001)$. ApoB100 level, on the other hand, was significantly raised in Pts which was reduced significantly after cholecystectomy, but not to the full extent as NCs and bile (Pts) contained lower levels of ApoB100 ( $<<0.001)$. Similarly, ApoE was significantly raised in Pts which was reduced significantly after 2-3 months of laparoscopic cholecystectomy, but not to the full extent similar to NCs and bile (Pts) contained lower level of ApoE $(\mathrm{P}<0.001)[20,22]$.

Associations (correlations) among Lp(a) status between NCs and Pts preoperatively $\left(\mathrm{I}^{0}\right)$ and postoperatively $\left(\mathrm{II}^{0}\right)$ are presented in Table 1) Interestingly, significant Pearson corrections were obtained for Pts-Lp(a) ( $\left.\mathrm{I}^{0}\right)$ ) vs Pts-Lp(a) ( $\left.\mathrm{II}^{0}\right)(\mathrm{r}=0.851, \mathrm{P}=0.000)$, and Pts-Lp(a)(Bile- $\left.\mathrm{I}^{0}\right)$. Table 2 shows correlations (associations) for ApoA1 levels between NCs and Pts, although no significant correlations were noted among the groups compared $(\mathrm{P}<0.05)$. Associations (correlations) for ApoB100 levels between NCs and Pts are stated in Table 3 showing significant Pearson correlation between NCs-ApoB100 ( $\left.\mathrm{I}^{0}\right)$ vs Pts-ApoB100 $\left(\mathrm{I}^{0}\right)(\mathrm{r}=0.430, \mathrm{P}=0.022)$. Similarly, no significant Pearson correlations were obtained for ApoE levels in any of the groups compared as shown in Table 4 $(\mathrm{P}>0.05)$.

Table 1: Associations among Lp(a) levels between normal control subjects (NC) and Patients (Pts) before $I^{\circ}$ and after cholecystectomy $\left(I^{\circ}\right)$.

\begin{tabular}{|c|c|c|c|c|c|}
\hline \multicolumn{2}{|c|}{ Parameters Compared* } & \multirow{2}{*}{$\begin{array}{c}\text { Pts-Lp(a) (mg/L), } \\
\left.\text { Serum (I }{ }^{\mathbf{0}} \text { degree }\right) \\
1\end{array}$} & \multirow{2}{*}{$\begin{array}{c}\text { Pts-Lp (a) (mg/L), } \\
\text { Bile (I degree) } \\
0.191\end{array}$} & \multirow{2}{*}{$\begin{array}{c}\text { Pts-Lp (a) (mg/L), Serum } \\
\text { (II degree) }\end{array}$} & \multirow{2}{*}{$\begin{array}{c}\text { NC-Lp (a) (mg/L), } \\
\text { Serum (I degree) } \\
-0.124\end{array}$} \\
\hline \multirow{3}{*}{$\begin{array}{l}\text { Pts-Lp (a) (mg/L), } \\
\text { Serum (I degree) }\end{array}$} & Pearson Correlation & & & & \\
\hline & Sig. (2-tailed) & & 0.311 & 0 & 0.485 \\
\hline & $\mathrm{N}$ & 44 & 30 & 34 & 34 \\
\hline \multirow{3}{*}{$\begin{array}{l}\text { Pts-Lp (a) (mg/L), Bile } \\
\text { (I degree) }\end{array}$} & Pearson Correlation & 0.191 & 1 & $.452^{*}$ & 0.016 \\
\hline & Sig. (2-tailed) & 0.311 & & 0.02 & 0.941 \\
\hline & $\mathrm{N}$ & 30 & 30 & 26 & 25 \\
\hline \multirow{3}{*}{$\begin{array}{l}\text { Pts-Lp (a) (mg/L), } \\
\text { Serum (II degree) }\end{array}$} & Pearson Correlation & $.851^{* *}$ & $.452^{*}$ & 1 & -0.019 \\
\hline & Sig. (2-tailed) & 0 & 0.02 & & 0.92 \\
\hline & $\mathrm{N}$ & 34 & 26 & 34 & 30 \\
\hline \multirow{3}{*}{$\begin{array}{l}\text { NC-Lp (a) (mg/L), } \\
\text { Serum (I degree) }\end{array}$} & Pearson Correlation & -0.124 & 0.016 & -0.019 & 1 \\
\hline & Sig. (2-tailed) & 0.485 & 0.941 & 0.92 & \\
\hline & $\mathrm{N}$ & 34 & 25 & 30 & 34 \\
\hline
\end{tabular}

Table 2: Correlations among ApoA1 levels between normal control subjects (NC) and Patients (Pts) before I0 and after cholecystectomy (II0).

\begin{tabular}{|c|c|c|c|c|}
\hline \multicolumn{5}{|c|}{ Correlations } \\
\hline \multicolumn{2}{|c|}{ Groups compared* } & $\begin{array}{c}\text { NC- Apo A1 (mg/dl), Serum } \\
\text { (I degree) }\end{array}$ & $\begin{array}{c}\text { Pts- Apo A1 (mg/dl), Serum (I } \\
\text { degree) }\end{array}$ & $\begin{array}{c}\text { Pts-Apo A1 (mg/dl), Serum (II } \\
\text { degree) }\end{array}$ \\
\hline \multirow{3}{*}{$\begin{array}{c}\text { NC- Apo A1 } \\
\text { (mg/dl), } \\
\text { Serum (I } \\
\text { degree) }\end{array}$} & Pearson Correlation & 1 & 0.038 & -0.032 \\
\hline & Sig. (2-tailed) & & 0.816 & 0.858 \\
\hline & $\mathrm{N}$ & 40 & 40 & 34 \\
\hline
\end{tabular}




\begin{tabular}{|c|c|c|c|c|}
\hline Pts- Apo & Pearson Correlation & 0.038 & 1 & 0.065 \\
\cline { 2 - 5 } A1 (mg/ & Sig. (2-tailed) & 0.816 & 55 & 0.674 \\
\cline { 2 - 5 } dI), Serum \\
(I degree) & $\mathrm{N}$ & 40 & 0.065 & 45 \\
\hline $\begin{array}{c}\text { Pts-Apo A1 } \\
\text { (mg/dl), }\end{array}$ & Pearson Correlation & -0.032 & 0.674 & 1 \\
\cline { 2 - 5 } $\begin{array}{c}\text { Serum (II } \\
\text { degree) }\end{array}$ & Sig. (2-tailed) & 0.858 & 45 & 45 \\
\hline
\end{tabular}

Table 3: Correlations among ApoB100 levels between normal control subjects (NC) and Patients (Pts) before $I^{\circ}$ and after cholecystectomy (II0).

\begin{tabular}{|c|c|c|c|c|}
\hline \multicolumn{5}{|c|}{ Correlations } \\
\hline \multicolumn{2}{|c|}{ Groups compared* } & $\begin{array}{c}\text { NC - Apo B100 (mg/dl), } \\
\text { Serum (I degree) }\end{array}$ & $\begin{array}{l}\text { Pts- Apo B100 (mg/dl), } \\
\text { Serum (I degree) }\end{array}$ & $\begin{array}{c}\text { Pts-Apo B100 (mg/dl), } \\
\text { Bile (I degree) }\end{array}$ \\
\hline \multirow{3}{*}{$\begin{array}{l}\text { NC - Apo B100 (mg/dl), } \\
\text { Serum (I degree) }\end{array}$} & Pearson Correlation & 1 & -0.076 & $.430 *$ \\
\hline & Sig. (2-tailed) & & 0.641 & 0.022 \\
\hline & $\mathrm{N}$ & 40 & 40 & 28 \\
\hline \multirow{3}{*}{$\begin{array}{l}\text { Pts- Apo B100 (mg/dl), } \\
\text { Serum (I degree) }\end{array}$} & Pearson Correlation & -0.076 & 1 & 0.151 \\
\hline & Sig. (2-tailed) & 0.641 & & 0.352 \\
\hline & $\mathrm{N}$ & 40 & 55 & 40 \\
\hline \multirow{3}{*}{$\begin{array}{l}\text { Pts-Apo B100 (mg/dl), Bile } \\
\text { (I degree) }\end{array}$} & Pearson Correlation & $.430^{*}$ & 0.151 & 1 \\
\hline & Sig. (2-tailed) & 0.022 & 0.352 & \\
\hline & $\mathrm{N}$ & 28 & 40 & 40 \\
\hline
\end{tabular}

Table 4: Correlations among ApoE levels between normal control subjects (NC) and Patients (Pts) before I0 and after cholecystectomy (II0).

\begin{tabular}{|c|c|c|c|c|}
\hline \multicolumn{5}{|c|}{ Correlations } \\
\hline \multicolumn{2}{|c|}{ Groups compared* } & $\begin{array}{l}\text { NC -Apo E (mg/ml), Serum } \\
\text { (I degree) }\end{array}$ & $\begin{array}{l}\text { Pts-Apo E (mg/ml), Serum } \\
\text { (I degree) }\end{array}$ & $\begin{array}{c}\text { Pts-Apo E (mg/ml), Serum } \\
\text { (II degree) }\end{array}$ \\
\hline \multirow{3}{*}{$\begin{array}{c}\text { NC -Apo E (mg/ml), Serum (I } \\
\text { degree })\end{array}$} & Pearson Correlation & 1 & 0.256 & -0.014 \\
\hline & Sig. (2-tailed) & & 0.111 & 0.937 \\
\hline & $\mathrm{N}$ & 40 & 40 & 34 \\
\hline \multirow{3}{*}{$\begin{array}{c}\text { Pts-Apo E (mg/ml), Serum (I } \\
\text { degree) }\end{array}$} & Pearson Correlation & 0.256 & 1 & 0.148 \\
\hline & Sig. (2-tailed) & 0.111 & & 0.333 \\
\hline & $\mathrm{N}$ & 40 & 55 & 45 \\
\hline \multirow{3}{*}{$\begin{array}{l}\text { Pts-Apo E (mg/ml), Serum (II } \\
\text { degree) }\end{array}$} & Pearson Correlation & -0.014 & 0.148 & 1 \\
\hline & Sig. (2-tailed) & 0.937 & 0.333 & \\
\hline & $\mathrm{N}$ & 34 & 45 & 45 \\
\hline
\end{tabular}

Associations among Lp(a) status and ApoA1 levels between NCs and Pts before $\left(\mathrm{I}^{0}\right)$ and after cholecystectomy $\left(\mathrm{II}^{0}\right)$ are presented in Table 5 showing no significant correlations among any of the groups compared ( $\mathrm{P}>0.05)$. Table 6 shows the associations (correlations) among Lp(a) status and ApoB100 between NCs and Pts before $\left(\mathrm{I}^{0}\right)$ and after cholecystectomy $\left(\mathrm{II}^{0}\right)$ indicating significant correlations between Pts- ApoB100 (II $\left.{ }^{0}\right)$ and Pts-Lp(a) (Bile- $\left.\mathrm{I}^{0}\right)$ $(\mathrm{r}=0.381, \mathrm{P}=0.05)$ and between NCs-Lp(a) $\left.\left(\mathrm{I}^{0}\right)\right)$ and Pts-ApoB100 $\left(\mathrm{II}^{0}\right)(\mathrm{r}=0.358, \mathrm{P}=0.05)$. Finally, significant Pearson correlation was obtained for NC-Lp(a) $\left(\mathrm{I}^{0}\right)$ vs Pts-ApoE $\left(\mathrm{II}^{0}\right)(\mathrm{r}=-0.447, \mathrm{P}=0.050)$ and other correlations were not significant $(\mathrm{P}>0.05)$ Table 7.

Table 5: Associations among Lp(a) levels and Apo A1 between normal control subjects (NC) and Patients (Pts) before 10 and after cholecystectomy (II0).

\begin{tabular}{|c|c|c|c|c|c|}
\hline \multicolumn{2}{|c|}{ Parameters Compared* } & $\begin{array}{c}\text { Pts-Lp(a) (mg/L), Se- } \\
\text { rum (I' } \text { ( }^{\mathbf{0}} \text { degree) }\end{array}$ & $\begin{array}{c}\text { Pts-Lp (a) (mg/L), } \\
\text { Bile (I degree) }\end{array}$ & $\begin{array}{c}\text { Pts-Lp (a) (mg/L), } \\
\text { Serum (II degree) }\end{array}$ & $\begin{array}{c}\text { NC-Lp (a) (mg/L), } \\
\text { Serum (I degree) }\end{array}$ \\
\hline \multirow{2}{*}{$\begin{array}{c}\text { Pts- Apo A1 (mg/ } \\
\text { dl), Serum (I } \\
\text { degree) }\end{array}$} & Pearson Correlation & -0.031 & -0.065 & -0.108 & 0.097 \\
\cline { 2 - 6 } & Sig. (2-tailed) & 0.841 & 0.734 & 0.543 & 0.585 \\
\hline
\end{tabular}




\begin{tabular}{|c|c|c|c|c|c|}
\hline \multirow{3}{*}{$\begin{array}{l}\text { Pts-Apo A1 (mg/ } \\
\text { dl), Bile (I degree) }\end{array}$} & Pearson Correlation & -0.023 & -0.25 & -0.072 & -0.025 \\
\hline & Sig. (2-tailed) & 0.903 & 0.183 & 0.726 & 0.907 \\
\hline & $\mathrm{N}$ & 30 & 30 & 26 & 25 \\
\hline \multirow{3}{*}{$\begin{array}{c}\text { Pts-Apo A1 (mg/ } \\
\text { dl), Serum (II } \\
\text { degree) }\end{array}$} & Pearson Correlation & 0.192 & -0.073 & 0.053 & 0.067 \\
\hline & Sig. (2-tailed) & 0.277 & 0.723 & 0.764 & 0.723 \\
\hline & $\mathrm{N}$ & 34 & 26 & 34 & 30 \\
\hline
\end{tabular}

Table 6: Associations among Lp(a) levels and Apo B100 between normal control subjects (NC) and Patients (Pts) before 10 and after cholecystectomy (IIO).

\begin{tabular}{|c|c|c|c|c|c|}
\hline \multicolumn{2}{|c|}{ Compared Parameters } & $\begin{array}{c}\text { Pts-Lp(a) (mg/L), Serum } \\
\text { (I degree) }\end{array}$ & $\begin{array}{l}\text { Pts-Lp (a) (mg/L), } \\
\text { Bile (I degree) }\end{array}$ & $\begin{array}{l}\text { Pts-Lp (a) (mg/L), } \\
\text { Serum (II degree) }\end{array}$ & $\begin{array}{l}\text { NC-Lp (a) (mg/L), } \\
\text { Serum (I degree) }\end{array}$ \\
\hline \multirow{3}{*}{$\begin{array}{l}\text { Pts- Apo B100 (mg/ } \\
\text { dl), Serum (I degree) }\end{array}$} & Pearson Correlation & -0.166 & 0.006 & -0.239 & 0.013 \\
\hline & Sig. (2-tailed) & 0.281 & 0.976 & 0.174 & 0.94 \\
\hline & $\mathrm{N}$ & 44 & 30 & 34 & 34 \\
\hline \multirow{3}{*}{$\begin{array}{l}\text { Pts-Apo B100 (mg/ } \\
\text { dl), Bile (I degree) }\end{array}$} & Pearson Correlation & -0.26 & 0.014 & -0.229 & -0.318 \\
\hline & Sig. (2-tailed) & 0.166 & 0.942 & 0.26 & 0.121 \\
\hline & $\mathrm{N}$ & 30 & 30 & 26 & 25 \\
\hline \multirow{3}{*}{$\begin{array}{c}\text { Pts-Apo B100 } \\
\text { (mg/dl), Serum (II } \\
\text { degree) }\end{array}$} & Pearson Correlation & 0.022 & 0.38 & 0.207 & 0.358 \\
\hline & Sig. (2-tailed) & 0.902 & 0.055 & 0.239 & 0.052 \\
\hline & $\mathrm{N}$ & 34 & 26 & 34 & 30 \\
\hline
\end{tabular}

Table 7: Associations among Lp(a) levels and Apo E between normal control subjects (NC) and Patients (Pts) before 10 and after cholecystectomy (II0).

\begin{tabular}{|c|c|c|c|c|c|}
\hline \multicolumn{2}{|c|}{ Compared Parameters } & $\begin{array}{l}\text { Pts-Lp(a) (mg/L), } \\
\text { Serum (I }{ }^{0} \text { degree) }\end{array}$ & $\begin{array}{l}\text { Pts-Lp (a) (mg/L), } \\
\text { Bile (I degree) }\end{array}$ & $\begin{array}{l}\text { Pts-Lp (a) (mg/L), } \\
\text { Serum (II degree) }\end{array}$ & $\begin{array}{c}\text { NC-Lp (a) (mg/L), Serum } \\
\text { (I degree) }\end{array}$ \\
\hline \multirow{3}{*}{$\begin{array}{l}\text { Pts-Apo E(mg/ml), } \\
\text { Serum (I degree) }\end{array}$} & $\begin{array}{l}\text { Pearson Correla- } \\
\text { tion }\end{array}$ & -0.08 & -0.07 & -0.147 & 0.129 \\
\hline & Sig. (2-tailed) & 0.605 & 0.715 & 0.406 & 0.466 \\
\hline & $\mathrm{N}$ & 44 & 30 & 34 & 34 \\
\hline \multirow{2}{*}{$\begin{array}{l}\text { Pts-Apo E (mg/ml), } \\
\text { Bile (I degree) }\end{array}$} & $\begin{array}{l}\text { Pearson Correla- } \\
\text { tion }\end{array}$ & -0.123 & -0.008 & 0.071 & 0.214 \\
\hline & Sig. (2-tailed) & 0.517 & 0.966 & 0.729 & 0.303 \\
\hline \multirow{3}{*}{$\begin{array}{l}\text { Pts-Apo E (mg/ml), } \\
\text { Serum (II degree) }\end{array}$} & $\begin{array}{l}\text { Pearson Correla- } \\
\text { tion }\end{array}$ & -0.148 & 0.071 & -0.224 & -0.347 \\
\hline & Sig. (2-tailed) & 0.403 & 0.731 & 0.203 & 0.06 \\
\hline & $\mathrm{N}$ & 34 & 26 & 34 & 30 \\
\hline
\end{tabular}

Correlation is significant at the 0.05 level $^{\star}$ (2-tailed) and at the 0.01 level $^{* \star}$ (2-tailed)

\section{Discussion}

The levels of Lp(a), ApoA1, ApoB100 and ApoE in Serum $I^{0}$, Bile $\mathrm{I}^{0}$ and Serum II $^{0}$ of NCs and cholelithiasis Pts were reported in our previous articles [20,22]. In the light of these reports, we evaluated the associations (correlations) among Lp(a) status, ApoA1, ApoB100 and ApoE levels between NCs and our Pts with cholelithiasis as stated in Table 1, Table 2, Table 3 and Table 4 respectively. Associations (correlations) among $\mathrm{Lp}(\mathrm{a})$ status and ApoA1, Lp(a) status and ApoB100 and Lp(a) status and ApoE levels between NCs and Pts $\left(\mathrm{I}^{0}, \mathrm{II}^{0}\right)$ are presented in Table 5, Table 6 and Table 7 respectively.
Our observations on Pts with cholelithiasis that serum Lp(a) level was significantly elevated and that significantly larger proportion of patients had higher serum Lp(a) levels were consistent with some reports in the literature from other countries [11-13]. Our findings on associations (correlations) of Lp(a)status between NCs and Pts stated in Table 1, Table 2, Table 3 and Table 4 indicated that $\mathrm{Lp}(\mathrm{a})$ along with ApoA1 and ApoB100 were involved in the process of GD. ApoE was not significantly associated with Lp(a) in our GD Pts which needs to be further investigated in future carefully designed studies in GD. These observations were substantiated by the findings of significant associations between 
Lp(a) and ApoB100 and Lp(a) and ApoE levels between NCs and Pts as stated in Table 6 and Table 7 respectively.

However, as stated in Table 5, the findings of no significant correlations among any of the groups compared for $\mathrm{Lp}(\mathrm{a})$ status and ApoA1 levels were difficult to explain and contradicted with the earlier findings stated in Table 2 . The reasons for this situation needs careful, relevant and logical explanations which clearly indicated that much more remained to be understood about the molecular events underlie these processes. A strong relationship between GD metabolic syndrome was reported recently suggesting that insulin resistance and leptin dysfunction might be responsible for reduced gallbladder motility which in turn may contribute to cholesterol gallstone formation $[14,17,25,26]$.

In overviews on the management of primary hyperlipidemia by statins, serum $\mathrm{Lp}(\mathrm{a})$ level and its reduction were not mentioned and considered in the discussion $[19,20,27,28]$. Even the updated National Cholesterol Education Programme (NCEP) report, USA published in July 2004 discussed and debated LDL-C only and no consideration for $\mathrm{Lp}(\mathrm{a})$ level was suggested in the NCEP report $[19,20,29]$.

Sarac et al. showed further that levels of ApoA1 were negatively correlated while ApoB100 levels were positively correlated with leptin [14]. Our findings on ApoE levels in patients with GD had similar trends as ApoB100 i.e. ApoE was increased in serum $\mathrm{I}^{0}$, followed by decrease in Serum- $\mathrm{II}^{0}$, significantly but not to the full extent as $\mathrm{NCs}(\mathrm{p}<0.001)$. ApoE is one of the key regulatory protein in cholesterol and lipoprotein metabolism and it has three common isoforms i.e. E2, E3, and E4. ApoE2 is a genetic factor providing protection against GD, while ApoE4 isoform may be a risk factor for cholelithiasis [22,30-32]. Our observation of increased serum ApoE level could mean either a protective or a susceptibility/risk factor role in GD. That means more studies are needed to establish these findings exploring other genetic loci that might affect GD risk. In a meta-analysis Li et al found insufficient evidence for the role of ApoE4 as GD risk factor [32].

Some prominent facts known about $\operatorname{Lp}(\mathrm{a})$ are that it is a genetically determined particle containing a ApoB-100 linked to ApoA1 and cholesterol lowering therapy i.e. cholestyramine treatment was not effective in lowering serum Lp(a) level although cholesterol level was reported to be reduced and Lp(a) has structural homology with plasminogen implicating in atherosclerosis and CADs $[10,11,20]$. Recently, antioxidant defense system has been implicated with the prevalence of GD and thought to play a role in the pathophysiology of GD and among them, higher circulating vitamin $\mathrm{E}$ and vitamin $\mathrm{C}$ levels have been suggested to provide protection against GD [22,33,34]. Apo A1, Apo E, CETP and mucin have been implicated with cholelithiasis in some studies [35-37]. Recently, it was reported that cholelithiasis patients have higher leptin levels and altered lipoprotein profile, with increased $L p(a)$ and ApoB levels and decreased ApoA1 levels [14]. Another study showed that symptomatic cholelithiasis patients have increased malondialdehyde (MDA) levels indicating lipid peroxidation and decreased antioxidant capacity [13]. Lp(a) is an enigmatic molecule having two components i.e. Apo(a) and ApoB100. Jaw et al recently opined that $\mathrm{Lp}(\mathrm{a})$ may be ready for prime time clinical use to monitor GD [38]. Abnormalities in lipids and apolipoproteins metabolism may, however, arise from a combination of various factors such as excess dietary cholesterol/fat, obesity, diabetes, deficient antioxidant system and genetic factors $[2,36,37,39,40]$.

In conclusion, the association of ApoB100 and ApoA1 structurally to $\mathrm{Lp}(\mathrm{a})$ and HDL respectively are important for metabolism of lipoproteins linked to GD i.e. cholelithiasis. Due to structural similarity to both LDL and plasminogen, Lp(a) may represent a link with cholelithiasis, atherosclerosis and thrombosis. Therefore, the changes in associations among Lp(a) status and apolipoproteins (A1, B100, E) are of crucial importance relevant to definitive role of the gallbladder leading to development of GD. Thus, incorporation of $\mathrm{Lp}(\mathrm{a})$ routinely in lipid profile analysis would be useful in identifying high risk patients and follow-up. Cholelithiasis had profound influence on ApoA1, ApoB100 and ApoE status suggesting their cause-and-effect roles in the complex aetiopathogenesis of the disease. More studies are warranted investigating these complex disease processes in cholelithiasis patients followed by cholecystectomy. It is also important to further study on metabolic syndrome in Bangladeshi patients with GD in future endeavors to substantiate the findings.

\section{Acknowledgements}

The authors appreciate medical technologists Mr. Taposh $\mathrm{K}$ Datta for laboratory analyses and Mr. M Nawjes Ali for computer composing the manuscripts. The authors also appreciate computer Programmer Mr. M Moniruzzaman Khan for composing the Tables and Mr. AHM Salman for statistical analyses. The authors gratefully acknowledge the financial supports from Ministry of Science and Technology (MOST), Government of the Republic of Bangladesh, Dhaka, Bangladesh and The Medical and Health Welfare Trust (MHWT), Dhaka, Bangladesh for the research projects.

\section{References}

1. Batajoo H, Hazra NK (2013) Analysis of serum lipid profile in cholelithiasis patients. J Nepal Health Res Counc 11(23): 53-55.

2. Rao PJ, Jarari A, Elawami H, Patil TN (2012) Lipid profile in bile and serum of cholelithiasis patients - A Comparative study. J Basic Med \& Allied Sci 1: 15-21.

3. Channa NA (2008) Gallstone disease: a review. Pak Arm Forces Med J 58: 197-208.

4. Portincasa P, Di Ciaula A, Vendemiale G, Palmieri V, Moschetta A, et al. (2000) Gallbladder motility and cholesterol crystallization in bile from patients with pigment and cholesterol gallstones. Eur J Clin Invest 30(4): 317-324. 
5. Malik AA, Wani ML, Tak SI, Irshad I, Ul-Hassan N, et al. (2011) Association of dyslipidaemia with cholelithiasis and effect of cholecystectomy on the same. Int J Surg 9(8): 641-642.

6. Skill NJ, Scott RE, Wu J, Maluffio MA (2011) Hepatocellular carcinoma associated lipid metabolism reprogramming. J Surg Res 169(1): 51-56.

7. Wang J, Shen S, Wang B, Ni X, Liu H, et al. (2020) Serum lipid levels are the risk factors of gallbladder stones: a population-based study in China. Lipids in Health and Dis 19(1): 50.

8. Pinheiro Júnior S, Pinhel MA, Nakazone MA, Pinheiro A, Amorim GF, et al. (2012) Effect of genetic variants related to lipid metabolism as risk factors for cholelithiasis after bariatric surgery in Brazilian population. Obes Surg 22(4): 623-633.

9. Danesh J, Collins R, Peto R (2000) Lipoprotein(a) and coronary heart disease. Meta-analysis of prospective studies. Circulation 102(10): 1082-1085.

10. Barghash NA, Elewa SM, Hamdi EA, Barghash AA, El Dine R, et al. (2004) Role of plasma homocysteine and lipoprotein (a) in coronary artery disease. Br J Biomed Sci 61(2): 78-83.

11. Giasuddin ASM, Jhuma KA, Mujibul Haq AM (2008) Lipoprotein (a) status in Bangladeshi patients with diabetes mellitus. J Med Coll Women Hosp 6: 74-82.

12. Haq AMM, Giasuddin ASM, Huque MM (2011) Serum total homocysteine and lipoprotein (a) levels in acute myocardial infarction and their response to treatment with vitamins. J Coll Physicians Surg Pak 21(5): 266-270.

13. Atamer A, Kurdas Ovunc AO, Yesil A, Atamer Y (2014) Evaluation of paraoxonase, malondialdehyde, and lipoprotein levels in patients with asymptomatic cholelithiasis. Saudi J Gastroenterol 20(1): 66-73.

14. Saraç S, Atamer A, Atamer Y, Can AS, Bilici A, et al. (2015) Leptin levels and lipoprotein profiles in patients with cholelithiasis. J Int Med Res 43(3): 385-392.

15. Devanapalli B, Lee S, Mahajan D, Bermingham M (2002) Lipoprotein (a) in an immigrant Indian population sample in Australia. Br J Biomed Sci 59(2): 119-122.

16. Gaw A, Brown EA, Gourlay CW, Bell MA (2000) Analytical performance of the Genzyme LipoPro Lp(a) kit for plasma lipoprotein(a)-cholesterol assay. Br J Biomed Sci 57(1): 13-18.

17. Chen LY, Qiao QH, Zhang SC, Chen YH, Chao GQ et al. (2012) Metabolic syndrome and gallstone disease. World J Gastroenterol 18(31): 42154220 .

18. Stender S, Frikke Schmidt R, Benn M, Nordestgaard BG, Tybjærg-Hansen A, et al. (2013) Low-density lipoprotein cholesterol and risk of gallstone disease: a Mendelian randomization study and meta-analyses. J Hepatol 58(1): 126-133.

19. Haq AMM, Giasuddin ASM, Jhuma KA, Choudhury MAM (2015) Effect of cholecystectomy on lipid profile in Bangladeshi patients with Cholelithiasis. J Metabolic Synd 5(1): 192.

20. Giasuddin ASM, Jhuma KA, Choudhury MAM, Haq AMM (2016) Lipoprotein (a) status and effect of laparoscopic cholecystectomy on it in Bangladeshi patients with Cholelithiasis. J Metabolic Synd 5(4): 216.

21. Choudhury MAM, Giasuddin ASM, Jhuma KA, Haq AMM (2018) Effects of Laparoscopic Cholecystectomy on Mucin1 and Cholesterol Ester Transfer Protein Status in Bangladeshi patients with Cholelithiasis. J Metabolic Synd 7(1): 240.

22. Jhuma KA, Giasuddin ASM, Chowdhury MAM, Haq AMM (2018) Effects of laparoscopic cholecystectomy on apolipoproteins (ApoA1, ApoB100, ApoE) status in Bangladeshi patients with cholelithiasis. J Clin Lab Med $3(1): 1-5$
23. Remaley AT, Rifai N, Warnick GR (2015) Lipids, lipoproteins, apolipoproteins and other cardiac risk factors. In: Burtis CA, et al. (Eds.) Tietz Fundamentals of Clinical Chemistry and Molecular Diagnostics ( $7^{\text {th }} \mathrm{Edn}$ ), St. Louise, Missouri: Elsevier Inc. (Saunders), USA, pp. 388-411.

24. Kirkwood BR, Sterne JAC (2008) Essential Medical Statistics (2 ${ }^{\text {nd }}$ Edn), Oxford: Blackwell Science Ltd.

25. Mendez Sanchez N, Chavez Tapia NC, Motola Kuba D, Sanchez Lara K, Ponciano Rodriguez G, et al. (2005) Metabolic syndrome as a risk factor for gallstone disease. World J Gastroenterol 11(11): 1653-1657.

26. Mendez Sanchez N, Bermejo Martinez LB, Vinals Y, Chavez Tapia NC, Graff IV, et al. (2005) Serum leptin levels and insulin resistance are associated with gallstone disease in overweight subjects. World J Gastroenterol 11(39): 6182-6187.

27. Khan MH, Khan AW, Aziz MM, Rabbi MA (2012) Day case laparoscopic cholecystectomy: experience at the Bangabandhu Sheikh Mujib Medical University. Mymensingh Med J 21(3): 485-489.

28. Ahmed T, Alam MT, Ahmed SU, Jahan M (2012) Role of intraoperative flexible choledochoscopy in calculus biliary tract disease. Mymensigh Med J 21(3): 462-468.

29. Anstee QM, Jones DEJ (2014) Lover and biliary tract disease. In: Walker BR, et al. (Eds.) Davidson's Principles and Practice of Medicine $\left(22^{\text {nd }}\right.$ Edn), Edinburgh: Churchill Livingstone Elsevier, pp. 921-988.

30. Bertomeu A, Ros E, Zambon D, Vela M, Pérez Ayuso RM, et al. (1996) Apolipoprotein E polymorphism and gallstones. Gastroenterology 111(6): 1603-1610.

31. Van Erpecum KJ, Carey MC (1996) Apolipoprotein E4: another risk factor for cholesterol gallstone formation? Gastroenterology 111(6): 17641767

32. Li L, Qiao X, Wang X, Liu D, Xue Q et al. (2019) The association between apolipoprotein $\mathrm{E}$ and gallstone disease: an updated meta-analysis. BMC Medical Genetics 20(1): 109.

33. Zhou JF, Chen P, Yang JL, Zhu YG, Peng CH, et al. (2000) Oxidative stress before and after operation in patients with chronic cholecystitis containing gallstone. Biomed Environ Sci 13(4): 254-262.

34. Waniek S, Giuseppe RD, Esatbeyoglu T, Ratjen I, Enderle J, et al. (2018) Association of circulating vitamin $\mathrm{E}$ ( $\alpha$-and $\beta$-tocopherol) levels with gallstone disease. Nutrients 10: Pp 133.

35. Hoque MM, Jhuma KA, Sultana P, Alam MM (2008) Apolipoproteins (B100 and A1) vs standard lipid measures (lipid profile) as indices of coronary heart disease risk. Should apolipoproteins replace the lipid profile? Bangladesh J Pathol 23: 4-7.

36. Ebadi P, Daneshmandi S, Ghasemi A, Karimi MH (2013) Cytokine single nucleotide polymorphisms in patients with gallstone: does TGF- $\beta$ gene variants affect gallstone formation? Mol Biol Rep 40(11): 6256-6260.

37. Vesper HW, Wilson PW, Rifai N (2012) A message from the laboratory community to the National Cholesterol Education Program Adult Treatment Panel IV. Clin Chem 58(3): 523-527.

38. Jaw MM, Frohlich J, Chan SY (2020) Lipoprotein (a) the insurgent: A new insight into the structure, function, metabolism, pathogenicity, and medications affecting Lipoprotein (a) molecule. J Lipids Pp. 3491764

39. Davidson MH, Ballantyne CM, Jacobson TA, Bittner VA, Braun LT, et al. (2011) Clinical utility of inflammatory markers and advanced lipoprotein testing: advice from an expert panel of lipid specialists. J Clin Lipidol 5(5): 338-367.

40. Koch M, Borggrefe J, Barbaresko J, Groth G, Jacobs G, et al. (2014) Dietary patterns associate with magnetic resonance imaging-determined liver fat content in a general population study. Am J Clin Nutr 99(2): 369-377. 